\title{
Monoclonal gammopathy of renal significance
}

\section{A short clinical approach}

\author{
Thomas Reiter (ID - Maja Nackenhorst
}

Received: 30 September 2020 / Accepted: 14 December 2020 / Published online: 6 January 2021

(C) The Author(s) 2021

Summary Monoclonal gammopathy of renal significance (MGRS) encompasses a group of kidney disorders in which a monoclonal immunoglobulin secreted by a B cell or plasma cell clone causes renal damage, without meeting hematological criteria for malignancy. The underlying disorder in patients with MGRS is generally consistent with monoclonal gammopathy of undetermined significance (MGUS). Because of the wide spectrum of MGRS-associated diseases, defined through the location and mechanism of renal injury, it is often challenging to establish the right diagnosis. Kidney biopsy must be considered early; hence, close cooperation between hematologist and nephrologists is crucial in diagnosis and treatment from the beginning to prevent irreversible organ damage. Anti B-cell or plasma-cell clone directed therapy with cytostatic or immunomodulatory agents can save and ameliorate renal function significantly. This is underlined by the fact that, untreated, MGRS-associated disease shows early recurrence in patients after kidney transplantation.

Keywords MGRS · Onco-nephrology · Monoclonal gammopathy $\cdot$ Renal failure $\cdot$ Monoclonal gammopathy of undetermined significance $\cdot$ Renal light-chain injury

\section{Abbreviations}

$\begin{array}{ll}\text { AL } & \text { Light chain amyloidosis } \\ \text { cHR } & \text { Complete hematological response }\end{array}$

\section{T. Reiter, MD ( $\square)$}

Division of Nephrology and Dialysis, Department of Medicine III, Medical University of Vienna, Vienna, Austria thomas.reiter@meduniwien.ac.at

M. Nackenhorst, MD

Department of Pathology, Medical University of Vienna, Vienna, Austria

\begin{tabular}{|c|c|}
\hline CKD & Chronic kidney disease \\
\hline CKD-EPI & Chronic Kidney Disease_Epidemiology \\
\hline & Collaboration \\
\hline FFPE & Formalin fixed paraffin embedded \\
\hline GBM & Glomerular basal membrane \\
\hline GFR & Glomerular filtration rate \\
\hline GN & Glomerulonephritis \\
\hline MGUS & $\begin{array}{l}\text { Monoclonal gammopathy of undeter- } \\
\text { mined significance }\end{array}$ \\
\hline MGRS & $\begin{array}{l}\text { Monoclonal gammopathy of renal signif- } \\
\text { icance }\end{array}$ \\
\hline MIDD & $\begin{array}{l}\text { Monoclonal immunoglobulin deposition } \\
\text { disease }\end{array}$ \\
\hline MM & Multiple myeloma \\
\hline MPGN & $\begin{array}{l}\text { Membranoroliferative glomerulonephri- } \\
\text { tis }\end{array}$ \\
\hline PGNMID & $\begin{array}{l}\text { Proliferative glomerulonephritis associ- } \\
\text { ated with monoclonal immune deposits }\end{array}$ \\
\hline POEMS & $\begin{array}{l}\text { Polyneuropathy, organomegaly, endo- } \\
\text { crinopathy, myeloma protein, and skin } \\
\text { changes }\end{array}$ \\
\hline RCT & Randomized controlled trial \\
\hline TMA & Thrombotic microangiopathy \\
\hline VGPR & Very good partial response \\
\hline
\end{tabular}

\section{Introduction}

In three percent of a general population over the age of 50 years, monoclonal gammopathy of undetermined significance (MGUS) can be found [1]. MGUS is defined as a premalignant condition, characterized by the presence of a monoclonal immunoglobulin or its fragments $<30 \mathrm{~g} / \mathrm{l}$ in serum and $<10 \%$ of monoclonal bone marrow plasma cells in a patient who does not show any further organ damage attributable to the monoclonal immunoglobulin [2]. The monoclonal immunoglobulins are either products of plasma cells or (small) B cell clones, as they occur in condi- 
tions such as multiple myeloma, chronic lymphatic leukemia (CLL), Waldenström's macroglobulinemia, or low-grade lymphoma.

Progression of MGUS to a hematologic malignancy shows a risk of $1 \%$ per year and is indicated by the occurrence of disease-defining events [3]. Multiple myeloma is defined by increase of FLC ratio (involved:uninvolved serum free light-chain ratio) $\geq 100$, an increase to monoclonal bone marrow plasma cells $\geq 60 \%$ or more than one lytic bone lesion over $5 \mathrm{~mm}$ in diameter on magnetic resonance imaging (MRI) [3]. All criteria of differentiation between a premalignant or malignant state include any form of tumor or cell burden.

However, a wide spectrum of renal injuries is associated with the presence of monoclonal immunoglobulins, aside from meeting criteria of hematologic malignancy. This indicates paraprotein-associated nephrotoxicity, independent from the serum-concentration of the toxic monoclonal protein is causal for the renal injury.

Taking this into account, in 2012, the International Kidney and Monoclonal Gammopathy Research Group (IKMG) introduced the term of monoclonal gammopathy of renal significance (MGRS) [4].

In a recent consensus statement, the definition was further narrowed and defined. The term MGRS now applies specifically to any clonal B-cell lymphoproliferative or clonal plasma-cell proliferative disease with two characteristics: First, one or more kidney lesions must be related to the (produced) monoclonal immunoglobulin. Second, the underlying B cell or plasma cell clone must not be detectable in peripheral blood or bone marrow. The disease-initiating paraprotein can be produced by a localized clonal disease-manifestation as localized plasmacytoma or localized lymph nodes in low grade non-Hodgkin lymphoma (NHL). Therefore not only blood, urine and bone marrow analses should be performed but also whole-body examination with CT scan or PETCT scan should be considered [5].

\section{When and why to think of MGRS}

The incidence of MGUS increases with age (3\% in patients $>50$ years, $5 \%$ in patients aged $>70$ years and up to $8 \%$ in patients aged 80 years or more) [5]. The incidence of chronic kidney disease (CKD) also increases up to $3.5 \%$ in Austria after the age of 60 years [6] and physiologically, glomerular filtration rate decreases after reaching its peak at the age of about 20 years. Therefore, a patient can have CKD and MGUS that are completely unrelated. It is crucial that nephrologists and hematologists cooperate closely to determine whether a renal impairment is caused by MGRS. The importance of this cooperation is underlined by the fact that patients with untreated MGRS are at high risk of developing end stage renal disease with dependence on maintenance dialysis or even the need of kidney transplantation. In a study of 19 patients with monoclonal immunoglobulin deposition disease (MIDD), an MGRS entity, renal survival was only $37 \%$ despite overall survival in this cohort being $70 \%$ [7]. Maintenance dialysis had worse unadjusted 5 -year survival $(50.8 \%$; 95\% confidence interval [CI] $50.1-51.6 \%)$ compared with prostate $(83.3 \%)$ and colorectal $(56.1 \%)$ cancer in men and worse unadjusted 5 -year survival $(49.8 \%)$ compared with breast $(82.1 \%)$ and colorectal (56.8\%) cancer in women [8]. Further, untreated MGRS has a high rate of recurrence in transplant recipients and can lead to rapid graft loss [9]. Therefore, any reluctance of treatment initiation critically reduces the patient's survival.

\section{Spectrum of disease and clinical manifestations}

MGRS encompasses a multitude of pathologies and clinical manifestations (Table 1). Regarding the location of the lesion in the kidney, the clinical presentation of MGRS may include a rapid decline in glomerular filtration rate and function by presence of proteinuria and/or albuminuria in small or even nephrotic range, hematuria or glucose and serum electrolyte disorders, indicating Fanconi syndrome cause by tubular injury. The pathologic spectrum of MGRS-associated disorders can mimic an otherwise classified renal diseases.

The most common renal manifestations in MGRS are renal light-chain amyloidosis (AL amyloidosis), monoclonal immunoglobulin deposition disease (MIDD) and cryoglobulinemic glomerulonephritis. Nevertheless, the monoclonal immunoglobulin can also work as a fully functional antibody and cause otherwise unrelated renal manifestations. For example, the monoclonal immunoglobulin can mimic antibodies directed against the renal glomerular basal membrane (GBM). In this case the patient would clinically present with Goodpasture syndrome, although regular antibodies against GBM could not be found with conventional assays [10]. As described in

Table 1 MGRS-associated diseases. (Modified from [5]) Monoclonal immunoglobulin deposits

\section{Organized}

Fibrillar Microtubular Inclusions/crystalline deposits

Immunoglobulin- Immunotactoid GN LCPT

related Amyloidosis

Monoclonal fibrillary Cryoglobulinaemic Crystal storing histiocytosis

GN GN type I \& II $\quad$ (Cryo) crystalglobulin GN

Non-organized

MIDD

Proliferative glomerulonephritis associated with monoclonal immune deposits (PGNMID)

No monoclonal immunoglobulin deposits

C3 glomerulopathy with monoclonal gammopathy

Thrombotic microangiopathy

GN glomerulonephritis, LCPT light chain proximal tubulopathy 
several case series monoclonal immunoglobulins can also act as antibodies against complement regulators and consequently cause thrombotic microangiopathy (TMA) [11].

In both of the examples above the determination of the underlying cell clone can be challenging. Hence, MGRS must be considered in all autoimmune renal disease as a rule-out diagnosis. A previously stated diagnosis must be re-evaluated, especially in clinical courses refractory to standard immunosuppression.

Untreated, MGRS-associated renal disease does unfortunately show early recurrence (60-89\%) after kidney transplantation and leads to rapid loss of allograft function $[12,13]$.

\section{Diagnostic approach}

Although most patients will present with symptoms of renal impairment, with proteinuria ( $>300 \mathrm{mg} /$ day) and with or without hematuria, all patients with MGUS should be screened on a regular (at least every 3 months) basis for the following parameters:

- Spot urine examination to determine proteinuria, albuminuria and hematuria, spot urine electrolytes.

- Serum creatinine and estimation of glomerular filtration rate (CKD-EPI)

- Serum electrolytes and glucose levels

If not previously performed, the lab work also includes serological and urine electrophoresis, immunofixation in serum and urine, and measurement of free light chain concentration in the serum and $24 \mathrm{~h}$ urine collection. Furthermore, a urinary sediment should be evaluated for hematuria or signs of nephritic changes. Immunofixation in $24 \mathrm{~h}$ urine collection can be pivotal to determine the underlying clone. In contrast, the urinary free light chain concentration in spot urine does not have any known value with regard to these disorders. For correct diagnosis and monitoring of a monoclonal paraprotein the free light chain concentration in $24 \mathrm{~h}$ urine collection is of pivotal importance.

Bone marrow biopsy for hematologic analysis and further whole-body examinations should be performed in accordance with the hematologists.

If the development of rapid deterioration of kidney function indicated by a decline of eGFR of $>2 \mathrm{ml} / \mathrm{min} / 1.73 \mathrm{~m}^{2}$ per year and the patient has a preknown MGUS, MGRS-associated disease must be suspected. These patients have to undergo kidney biopsy. This is the gold standard for diagnosis, and the complex histological workup will give guidance for the further treatment. Complications of kidney biopsies, such as major bleeding, are rare and compatible with those of renal transplant biopsies $(4.0$ and $3.3 \%$ respectively, $p=0.4$ ) (Table 2 ; $[14,15]$ ).
Table 2 Indications for renal biopsy. (Modified from [5])

\begin{tabular}{|c|c|c|c|c|}
\hline & $\begin{array}{l}\text { CKD } \\
\text { stage }\end{array}$ & eGFR (CKD-EPI) & Urine findings & $\begin{array}{l}\text { Other } \\
\text { findings }\end{array}$ \\
\hline $\begin{array}{l}\text { Biopsy } \\
\text { advised }\end{array}$ & $\begin{array}{l}3 \text { and } \\
\text { higher }\end{array}$ & $\begin{array}{l}<60 \mathrm{ml} / \mathrm{min} / 1.73 \mathrm{~m}^{2} \\
\& \\
\text { decline } \\
>2 \mathrm{ml} / \mathrm{min} / 1.73 \mathrm{~m}^{2} / \\
\text { year }\end{array}$ & $\begin{array}{l}\text { Proteinuria, hematuria } \\
\text { Albumin:creatinine ratio } \\
>300 \mathrm{mg} / \mathrm{dl}\end{array}$ & $\begin{array}{l}\text { Fanconi } \\
\text { syndrome } \\
\text { (hy- } \\
\text { pourice- } \\
\text { mia) }\end{array}$ \\
\hline $\begin{array}{l}\text { Biopsy } \\
\text { consid- } \\
\text { ered }\end{array}$ & 1.2 & $<60 \mathrm{ml} / \mathrm{min} / 1.73 \mathrm{~m}^{2}$ & $\begin{array}{l}\text { Albumine:creatinine } \\
\text { ratio } 30-300 \mathrm{~m} \mathrm{mg} / \mathrm{dL} \\
\text { Hematuria } \\
\text { Evidence of light chain } \\
\text { proteinuria }\end{array}$ & - \\
\hline
\end{tabular}

Epidemiology Collaboration, CKD chronic kidney diseases

\section{Histological findings}

While clinical manifestations are associated with the renal location of the lesion, the systematic classification of MGRS is guided by the type of organization of monoclonal immunoglobulins in the lesion. Basically MGRS lesions are divided into organized and nonorganized patterns with several subdivisions and further into non-immunoglobulin deposit conditions (Table 1). MGRS has an abundance of light-microscopic and ultrastructural manifestations that can be challenging to interpret [16].

Light microscopy: For a first overview $2-3 \mu \mathrm{m}$ sections from formalin fixed and paraffin embedded (FFPE) material are stained with HE (hematoxilineosin), PAS, a silver stain (see Fig. 1) and a trichrome stain. This allows a first assessment of predominant pathologies, like deposition of matrix suspicious for amyloidosis in glomeruli, blood vessels and/or the interstitium; thickening of the intraglomerular capillary walls potentially indicating immune-complex or light chain deposition; "hyaline" thrombi in glomerular capillaries as seen in cryoglobulinemia; or tubular casts suspicious for cast nephropathy. For the diagnosis of amyloid deposition a positive Congo red stain (apple-green birefringence under polarized light) performed on a $5-6 \mu \mathrm{m}$ thick section from FFPE material is mandatory and is at times essential to detect small deposits that can be easily overlooked in other stains $[17,18]$.

Immunohistochemistry/Immunofluorescence: Multiple MGRS-associated pathologies show immunohistochemical abnormalities (light chain restrictions in cast nephropathy and AL amyloidosis, LCDD (Light Chain Deposition Disease), C3 deposits in C3 glomerulopathies, etc.). It is imperative to distinguish these entities by thorough immunohistochemical analysis with staining for IgG, IgM, IgA, C3 and C1q as well as kappa and lambda light chains to identify monotypic deposits. This can be performed by immunohistochemistry on FFPE material with the advantage of colocalizing deposition of immunoglob- 


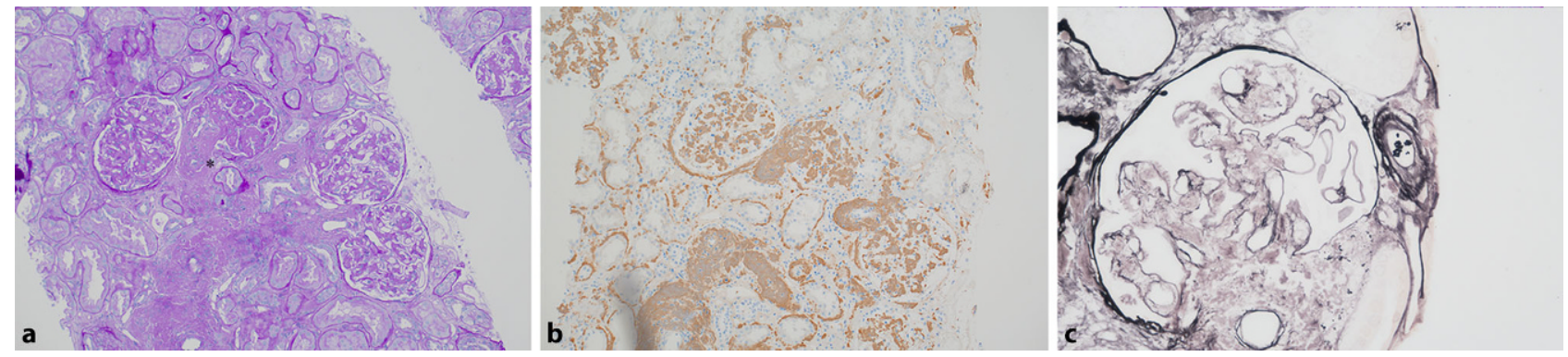

Fig. 1 Renal AL amyloidosis. a PAS staining; showing interstitial and glomerular, hyaline and amorphous deposits (asterisk). b Lambda light-chain staining; identifying amyloid as

ulins and/or complement factors to regions of interest seen in histological stains. Alternatively, as it is custom in several countries, a second core or part of the renal biopsy can be used unfixed for direct or indirect immunofluorescence on frozen sections. This method may be beneficial in case of high background sometimes seen in sections from FFPE material and thus higher specificity. (see Fig. 1)

Ultrastructural analysis: The last step to define the MGRS manifestation is the ultrastructural analysis. Electron microscopy can confirm light chain deposition disease and help to differentiate between intramembranous, subepithelial and subendothelial deposits, but also identifies mesangial deposits. Further, it can define the structure of deposits seen: Fibrillary deposits are found in Ig-related amyloidosis and fibrillary glomerulonephritis (GN), microtubules are found in immunotactoid GN and can be found in type 1 cryoglobulinemic GN [19, 20]. Crystal formation can be found in light chain proximal tubulopathy and crystal storing histocytosis [21, 22]. Nonorganized deposits are found in the monoclonal immunoglobulin deposition diseases (MIDD), PGNMID and C3 glomerulopathy, with associated monoclonal gammopathy. C3 glomerulopathy encompasses dense deposit disease (DDD) with prominent intramembranous and to a lesser extent mesangial deposits, as well as C3 glomerulonephritis with less well defined mesangial, intramembranous and subendothelial deposits [23].

\section{Treatment}

After diagnosis of an MGRS-associated disease, therapy should be initiated immediately. The goal of MGRS therapy is to eliminate the underlying clone, while preserving or ameliorating kidney function. The clonal-directed treatment should be managed by hematologists and nephrologists in close cooperation. For the management of these complex diseases interdisciplinary cooperation between nephrologists, hematologists, specialized nephropathologists, radiologists and transplant specialists is of utmost importance. Thus, diagnosis and treatment should be lambda light-chain restricted. c Methenamine silver staining; amyloid is not stained and leaving lacunae in basal membrane. Copyright is with the author

performed in specialized centers with high level of experience.

\section{Take home message}

Untreated, MGRS leads to end stage renal disease and unfortunately, to rapid loss of graft function in patients after kidney transplantation. Interdisciplinary cooperation is crucial for renal and overall survival.

Funding Open Access funding provided by Medical University of Vienna

Conflict of interest T. Reiter and M. Nackenhorst declare that they have no competing interests.

Open Access This article is licensed under a Creative Commons Attribution 4.0 International License, which permits use, sharing, adaptation, distribution and reproduction in any medium or format, as long as you give appropriate credit to the original author(s) and the source, provide a link to the Creative Commons licence, and indicate if changes were made. The images or other third party material in this article are included in the article's Creative Commons licence, unless indicated otherwise in a credit line to the material. If material is not included in the article's Creative Commons licence and your intended use is not permitted by statutory regulation or exceeds the permitted use, you will need to obtain permission directly from the copyright holder. To view a copy of this licence, visit http://creativecommons.org/licenses/by/4.0/.

\section{References}

1. Kyle RA, Therneau TM, Rajkumar SV, Larson DR, Plevak MF, Offord JR, et al. Prevalence of monoclonal gammopathy of undetermined significance. N Engl J Med. 2006;354(13):1362-9.

2. Kyle RA. Monoclonal gammopathy of undetermined significance. Natural history in 241 cases. Am J Med. 1978;64(5):814-26.

3. Rajkumar SV, Dimopoulos MA, Palumbo A, Blade J, Merlini G, Mateos MV, et al. International myeloma working group updated criteria for the diagnosis of multiple myeloma. Lancet Oncol. 2014;15(12):e538-e48.

4. Leung N, Bridoux F, Hutchison CA, Nasr SH, Cockwell P, Fermand JP, et al. Monoclonal gammopathy of renal significance: when MGUS is no longer undetermined or insignificant. Blood. 2012;120(22):4292-5.

5. Leung N, Bridoux F, Batuman V, Chaidos A, Cockwell P, D'Agati VD, et al. The evaluation of monoclonal gam- 
mopathy of renal significance: a consensus report of the International Kidney and Monoclonal Gammopathy Research Group. Nat Rev Nephrol. 2019;15(1):45-59.

6. StatistikAustria. Chronische Krankheiten und Gesundheitsprobleme 2014. 2015. http://www.statistik.at/wcm/idc/ idcplg?IdcService=GET_PDF_FILE\&RevisionSelectionMet hod=LatestReleased $\&$ dDocName $=105604$. Accessed 8 Dec 2020.

7. Heilman RL, Velosa JA, Holley KE, Offord KP, Kyle RA. Longterm follow-up and response to chemotherapy in patients with light-chain deposition disease. Am J Kidney Dis. 1992;20(1):34-41.

8. Naylor KL, Kim SJ, McArthur E, Garg AX, McCallum MK, Knoll GA. Mortality in incident maintenance dialysis patients versus incident solid organ cancer patients: a population-based cohort. Am J Kidney Dis. 2019;73(6):765-76.

9. Leung N, Lager DJ, Gertz MA, Wilson K, Kanakiriya S, Fervenza FC. Long-term outcome of renal transplantation in light-chain deposition disease. Am J Kidney Dis. 2004;43(1):147-53.

10. Borza DB, Chedid MF, Colon S, Lager DJ, Leung N, Fervenza FC. Recurrent Goodpasture's disease secondary to a monoclonal IgAl-kappa antibody autoreactive with the alpha1/alpha2 chains of type IV collagen. Am J Kidney Dis. 2005;45(2):397-406.

11. Ravindran A, Go RS, Fervenza FC, Sethi S. Thrombotic microangiopathy associated with monoclonal gammopathy. KidneyInt. 2017;91(3):691-8.

12. Czarnecki PG, Lager DJ, Leung N, Dispenzieri A, Cosio FG, Fervenza FC. Long-term outcome of kidney transplantation in patients with fibrillary glomerulonephritis or monoclonal gammopathy with fibrillary deposits. Kidney Int. 2009;75(4):420-7.

13. Herrmann SM, Gertz MA, Stegall MD, Dispenzieri A, Cosio FC, Kumar S, et al. Long-term outcomes of patients with light chain amyloidosis (AL) after renal transplantation with or without stem cell transplantation. Nephrol Dial Transplant. 2011;26(6):2032-6.

14. Fish R, Pinney J, Jain P, Addison C, Jones C, Jayawardene S, et al. The incidence of major hemorrhagic complications after renal biopsies in patients with monoclonal gammopathies. Clin JAm Soc Nephrol. 2010;5(11):1977-80.

15. Ciocchini M, Musso CG. Why renal biopsy is crucial in monoclonal gammopathy of renal significance (MGRS). Int Urol Nephrol. 2019;51(5):899-900.
16. Bridoux F, Leung N, Hutchison CA, Touchard G, Sethi S, Fermand JP, et al. Diagnosis of monoclonal gammopathy of renal significance. Kidney Int. 2015;87(4):698-711.

17. Howie AJ, Brewer DB. Optical properties of amyloid stained by Congo red: history and mechanisms. Micron. 2009;40(3):285-301.

18. Picken MM.Modernapproaches to the treatment ofamyloidosis: the critical importance of early detection in surgical pathology. AdvAnat Pathol. 2013;20(6):424-39.

19. Said SM, Sethi S, Valeri AM, Leung N, Cornell LD, Fidler ME, et al. Renal amyloidosis: origin and clinicopathologic correlations of 474 recent cases. Clin J Am Soc Nephrol. 2013;8(9):1515-23.

20. Bridoux F, Hugue V, Coldefy O, Goujon JM, Bauwens M, Sechet A, et al. Fibrillary glomerulonephritis and immunotactoid (microtubular) glomerulopathy are associated with distinct immunologic features. Kidney Int. 2002;62(5):1764-75.

21. Kapur U, Barton K, Fresco R, Leehey DJ, Picken MM. Expanding the pathologic spectrum of immunoglobulin light chain proximal tubulopathy. Arch Pathol Lab Med. 2007;131(9):1368-72.

22. ElHamelC, ThierryA, Trouillas P, BridouxF, Carrion C, Quellard N, et al. Crystal-storing histiocytosis with renal Fanconi syndrome: pathological and molecular characteristics compared with classical myeloma-associated Fanconi syndrome. Nephrol Dial Transplant. 2010;25(9):2982-90.

23. Pickering MC, D'Agati VD, Nester CM, Smith RJ, Haas M, Appel GB, et al. C3 glomerulopathy: consensus report. KidneyInt. 2013;84(6):1079-89.

Publisher's Note Springer Nature remains neutral with regard to jurisdictional claims in published maps and institutional affiliations.

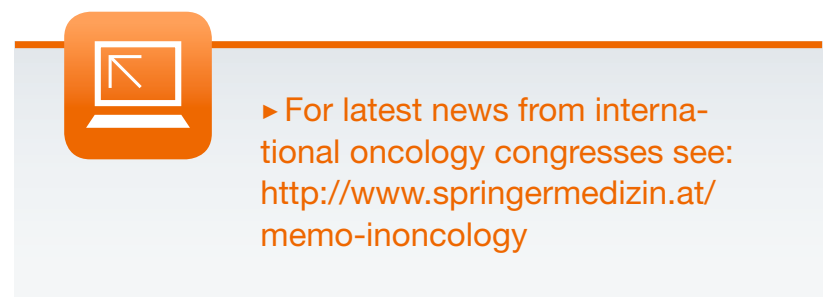

